\title{
en-claves
}

\section{LA DEMOCRACIA Y EL GIRO ESPACIAL DE LA FILOSOFÍA POLÍTICA}

\author{
Democracy and The Spatial Turn in Political Philosophy
}

\author{
Alejandro Sahuí, Universidad Autónoma de Campeche, México \\ Correo electrónico: alesahui@hotmail.com
}

Recepción: 19/08/2019

Aceptación: 11/02/2020

Resumen. El propósito de este texto es reflexionar en torno a la dimensión espacial de la política y la democracia. El problema es que la dimensión del espacio, de los lugares físicos en los que se desarrolla la vida social y se reclaman bienes colectivos, públicos y derechos, no ha sido tematizado suficientemente por la filosofía política como un asunto que tenga densidad propia en términos normativos. Dado que la democracia se asocia al Estado nacional es como si el espacio físico fuera uniforme y su población homogénea, como si el mismo conjunto de procedimientos y reglas fueran adecuadas para administrar en forma neutral las demandas de las personas y grupos en cualquier escenario. Se trata de visibilizar que la configuración de los espacios como lugares de la experiencia humana condiciona aquello sobre lo que se puede hablar, cómo hacerlo y quiénes puedan participar.

Palabras clave: democracia, giro espacial, filosofía política, democratización del Estado, espacio público.

\begin{abstract}
The purpose of this paper is to reflect around the spatial dimension of politics and democracy. The problem is that the dimension of space - the physical places where social and collective life take place and public rights are claimed - have not been given a central stage as a proper subject by political philosophy in normative terms. Since democracy is connected to national state, it is commonly assumed that physical space is uniform and its population homogeneous, as if the same set of procedures and rules were adequate to manage in a neutral way the demands of people and groups in any scenario. This text tries to make visible that the configuration of spaces as places of human experience determines what we can talk about, how to do it, and who can participate in the conversation.
\end{abstract}

Keywords: Democracy, spatial turn, political philosophy, democratization of the State, public space. 


\section{enn-claves}

\section{Introducción}

En el ámbito de la ciencia política, Guillermo O’Donnell ha llamado la atención acerca de la distinción entre la democracia como régimen y el Estado: ${ }^{1}$ la democracia como régimen se refiere a los procedimientos a través de los que se organiza en condiciones de libertad y de igualdad la selección, elección y control de los representantes políticos; el Estado, en cambio, trata de la organización legal y administrativa del territorio y de la población.

Con un sentido semejante, Jordi Borja y Manuel Castells observan la diferencia entre las nociones de ciudad y urbanización. La ciudad se asocia con la idea de régimen político como "sistema específico de relaciones sociales, de cultura y, sobre todo, de instituciones políticas de autogobierno", ${ }^{2}$ cuyos habitantes gozan del mismo estatus de ciudadanía. En la ciudad se puede transitar, ocupar y permanecer en todo tipo de lugares. ${ }^{3}$ Por su parte, la urbanización se refiere a las variadas formas de articulación espacial de la población y sus actividades. ${ }^{4}$ La urbanización es la instancia que organiza jurídicamente a la población en un territorio. Urbanizar es aterrizar la vida personal, social y productiva de una comunidad particular en un espacio físico concreto, histórico, contingente.

Las concepciones de política y policía de Jacques Rancière sugieren una distinción similar: la política — como el régimen o la ciudad - presupone un lugar público común, además de la existencia y calidad de iguales de quienes están presentes. Mientras que la policía - igual que el Estado o la urbanización - trata del conjunto de reglas mediante las que se realiza la agregación de las personas, la distribución de los lugares físicos, funciones y sistemas de legitimación. ${ }^{5}$

Al visibilizar estas distinciones, este texto trata de poner de manifiesto cómo las diferentes formas de organizar el espacio físico, las esferas de competencia, la

\footnotetext{
${ }^{1}$ Guillermo O’Donnell, Democracia, agencia y Estado. Teoría con intención comparativa (Buenos Aires, Prometeo Libros: 2010), 373.

2 Jordi Borja y Manuel Castells, Local y global. La gestión de las ciudades en la era de la información (Madrid: Taurus, 1997), 13.

${ }^{3}$ Sobre este tema, véase Henri Lefebvre, El derecho a la ciudad (Península: Barcelona, 1978), 168.

${ }^{4}$ Ibid., 13.

${ }^{5}$ Jacques Rancière, El desacuerdo. Política y filosofía (Buenos Aires: Nueva Visión, 1996), 41-43.
} 


\section{enn-claves}

arquitectura de los lugares y la dinámica de las instituciones y prácticas sociales tienen efectos - deliberados o no- sobre las personas. Sin embargo, el trabajo no versa exactamente sobre los distintos órdenes formales de la representación política -local, nacional o global - sino acerca de la dimensión personal: cómo se experimenta la agencia por parte de sujetos que participan en distintos ámbitos de manera simultánea. Que lo hagan o no en el seno de instituciones democráticas en condiciones de igualdad y libertad, o sea, con autonomía y capacidad de autodeterminación, es algo que tiene que ver con la estructura, dinámica y composición de dichos lugares, que pueden ser aliciente u óbice para el ejercicio de tales derechos y valores.

Esto significa que el grado de cohesión, o de inclusión/exclusión de la pluralidad de todo Estado, urbanización y policía queda reflejada en la distribución de competencias estatales, en la arquitectura urbana de la ciudad, en la disposición de su espacialidad y usos públicos — privados o sociales - y en la distribución del territorio a partir de distintivos de clase, de estatus y de multiculturalidad: ¿quiénes participan y cómo?; ¿quiénes están dentro y quiénes excluidos?

La invisibilidad de las mujeres, de las personas LGBTTTIQ, con discapacidad, mayores, jóvenes, indígenas en lugares laborales, políticos, profesionales, empresariales, educativos, de socialización y recreo, son un signo del incumplimiento de sus derechos y libertades.

Incluso los sectores y las clases medias de población son condicionados a ciertas maneras de comportarse que los ocultan y silencian respecto de las élites sociales y clases altas. Éste es el punto de vista de Christophe Guilluy sobre la pérdida de estatus de las clases medias y su desaparición del espacio público como referentes culturales. ${ }^{6}$ Por eso, Guilluy señala la singularidad del movimiento de chalecos amarillos en Francia, cuyo atuendo en sí mismo — de señal de alerta — proyecta el reclamo de visibilidad, de decir "¡aquí estamos!". 7

\footnotetext{
${ }^{6}$ Christophe Guilluy, No Society. El fin de la clase media occidental (Barcelona: Penguin Random House, 2019), edición Kindle.

7 "Entrevista a Christophe Guilluy: 'El problema de la izquierda es que está encerrada en su sociología y en las grandes ciudades'", de Daniel Gascón, en Letras Libres, 8 de julio, 2019,
} 


\section{enn-claves}

Enfrente de la fenomenología del Estado, la urbanización y la policía —instancias todas ellas contingentes, históricas y localizadas-, pensar las nociones de democracia, ciudad y política como referentes conceptuales proporciona un auxilio heurístico para descubrir las formas en que las personas puedan ser real y materialmente igualadas en el territorio físico y en los diferentes sitios y lugares en los que se desarrolla la vida humana.

En cierta forma, se podría confrontar cada par de conceptos enunciados democracia/Estado, ciudad/urbanización, y política/policía en la lógica con la que John Rawls propone la idea de 'equilibrio reflexivo', incluso en la esfera cosmopolita. ${ }^{8} \mathrm{Se}$ trataría de buscar el recíproco acomodamiento entre los ideales de igualdad y libertad que reclaman democracia, ciudad y política cuando éstos aterrizan y se implantan en sitios y lugares con específicas lógicas, dinámicas y rutinas. Eventualmente, en algunos de estos espacios se opondrá resistencia a que todas las personas y grupos dispongan del mismo trato igual. O’Donnell, por ejemplo, propone la democratización del Estado, y Carlos Pereyra llama a democratizar tanto la gestión pública como la fábrica y el conjunto de la vida social, barrios, etcétera. ${ }^{9}$

En términos planteados por Edward Soja, una perspectiva espacial ayudaría a comprender mejor cómo la justicia social es perseguida como un objetivo de la acción democrática. ${ }^{10}$ Bajo una óptica semejante a la indicada antes del equilibrio reflexivo, Soja sostiene que hay una dialéctica o relación mutuamente influyente entre las dimensiones social y espacial, en la que cada una perfila y condiciona a la otra, pero sin capacidad de sobredeterminarla. ${ }^{11}$ La justicia espacial no sustituye a otras concepciones de la justicia, sino que básicamente ofrece una perspectiva interpretativa acerca de la política.

\footnotetext{
https://www.letraslibres.com/espana-mexico/politica/entrevista-christophe-guilluy-el-problema-laizquierda-es-que-esta-encerrada-en-su-sociologia-y-en-las-grandes-ciudades.

${ }^{8}$ Para John Rawls el equilibrio reflexivo debe permitir que los principios de justicia construidos o encontrados en la base de un consenso traslapado en sociedades con democracias bien ordenadas se acomoden con las intuiciones profundas y con los juicios individuales meditados de la gente. Véase John Rawls, La justicia como equidad. Una reformulación (Barcelona: Paidós, 2002), 55-58; también así se puede comprender el ejercicio de Rawls en El derecho de gentes y "Una revisión de la idea de razón pública" (Barcelona: Paidós, 2001).

${ }^{9}$ Carlos Pereyra, Sobre la democracia (México: IEPCEJ, 2012), 120.

${ }^{10}$ Edward Soja, Seeking Spatial Justice (Minneapolis: University of Minnesota Press, 2010), 2.

${ }^{11}$ Ibid., 4.
} 


\section{enn-claves}

La idea de Soja es semejante en este punto a la de Susan S. Fainstein. Esta autora, a través de específicos resultados, más que de los procesos decisionales o de las concepciones de la justicia, es como se puede realizar una 'teoría de la justicia urbana'. Los resultados deseables en esta dirección serían equidad, democracia y diversidad. ${ }^{12} \mathrm{La}$ democracia y la justicia no se pueden pensar desvinculadas de las condiciones sociales, de la ciudad física ni tampoco de cómo las personas - agentes - experimentan su participación en ellas.

\section{La agencia autónoma: de Kant a Grecia y viceversa.}

Al inicio se observó la diferencia entre la democracia y el Estado, señalada por Guillermo O’Donnell. Esta diferencia está atravesada por una idea clave — la agencia autónomaque, al mismo tiempo que sirve para distinguir estas nociones, las asocia, convirtiendo a la persona en el centro de lo político. Pero persona no es cualquier individuo a secas. En términos de O’Donnell, es el ciudadano con derechos políticos de participación: la agencia humana "da sentido y fundamento a la ciudadanía", ${ }^{13}$ y está a la base de la democracia. Ésta no equivale a cualquier tipo de comportamiento: "involucra complicadas cuestiones filosóficas, morales y psicológicas [...] un agente es alguien dotado de razón práctica y discernimiento moral". ${ }^{14}$ Supone que existe un ser intencional que no es puramente reactivo, que es responsable de sus decisiones y de las consecuencias que siguen de ellas. ${ }^{15}$ Parece inevitable pensar en la autonomía kantiana al postular la agencia en estos términos.

David Harvey ha señalado el interés de Immanuel Kant en la geografía y la antropología, disciplinas que han sido descuidadas en la investigación de su pensamiento moral y político. De modo especial, sus estudios sobre geografía no se han muy en

\footnotetext{
${ }^{12}$ Susan S. Fainstein, "Planificación, Justicia y Ciudad", Urban, núm. 6 (septiembre-diciembre, 2014): 720; véase también Susan S. Fainstein, The Just City (Ithaca, NY: Cornell University Press, 2011), edición Kindle.

${ }_{14}^{13}$ O'Donnell, Democracia, agencia y Estado, 47.

${ }^{14}$ Ibid., 50.

${ }^{15}$ Ibid., 50.
} 


\section{enn-claves}

serio. ${ }^{16}$ Pero, si explícitamente Kant creía que ambas materias brindaban las condiciones de posibilidad de todo tipo de conocimiento, parece importante indagar sobre las formas de organización del territorio, del espacio físico que sería capaz de albergar una ética que ordena reflexionar simultáneamente como individuos con capacidad de autonomía en lo personal, como ciudadanos con capacidad de autodeterminación en el Estado y como integrantes de una república mundial o cosmopolita (cuyo espacio no existe todavía). ${ }^{17}$ En cada uno de estos planos las personas deben contar con la calidad de agentes, de ser libres y responsables. El enfoque moral de los individuos privados tendría la mira puesta en el bienestar propio y en la felicidad; el de los ciudadanos de un Estado, en la justicia política, y el de los ciudadanos del mundo o cosmopolitas pretendería el bien de la especie humana.

La crítica de Harvey contra la invisibilización de la geografía en Kant afecta, por ejemplo, a la principal concepción de la justicia política contemporánea, la justicia como equidad de Rawls. ${ }^{18}$ Es bien sabido que Rawls aterriza la idea de justicia en las instituciones del Estado-nación como entidades cerradas que las personas no pueden eludir. $^{19}$

Nancy Fraser ha desarrollado la idea de hacer trascender a la justicia del ámbito Estatal-nacional. La autora critica el enmarque westfaliano de la política donde estaría situado Rawls. Este marco concebía a los Estados como unidades geográficamente delimitadas, sobre las que ejercían una soberanía indivisa y exclusiva. Sin embargo, no se puede mantener una ficción semejante dado el orden internacional actual y el tamaño de los problemas que se enfrentan. El problema del enmarque o de las escalas de la justicia —el enfoque del mapa - se relaciona con la agencia personal: ¿quién es el auténtico

\footnotetext{
16 "Este abandono histórico de la Geografía no se corresponde con la valoración del propio Kant. De hecho, se desvivió por conseguir que la universidad le permitiese enseñar geografía en lugar de cosmología. Impartió clases de geografía en cuarenta y nueve ocasiones, mientras que de lógica y metafísica lo hizo cincuenta y cuatro, y de ética y antropología fueron cuarenta y seis y veintiocho, respectivamente. Sostenía explícitamente que la geografía y la antropología determinaban las 'condiciones de posibilidad' de todo conocimiento", David Harvey, El cosmopolitismo y las geografias de la libertad (Madrid: Akal, 2017), edición Kindle, loc. 465.

${ }^{17}$ Immanuel Kant, Teoría y práctica (Madrid: Tecnos, 1993), 7.

${ }^{18}$ Rawls, La justicia.

${ }^{19}$ Rawls, El derecho, 222.
} 


\section{enn-claves}

sujeto de la justicia: las ciudadanías territorializadas, la humanidad global o las comunidades de riesgo transnacionales? $?^{20}$

Esta es la crítica hecha por Harvey a David Held, relacionándola con sus estudios sobre la gobernanza global y el cosmopolitismo por niveles. Este tipo de cosmopolitismo exige debates localizados sobre asuntos políticos y morales de una "complejidad hermenéutica ineludible" ${ }^{21}$ en un mundo donde aparecen fragmentadas las responsabilidades personales, la sostenibilidad y la rendición de cuentas.

Por lo tanto, no son poco relevantes las diferentes maneras de ser un agente cosmopolita, las distintas formas de estar en el mundo. No es lo mismo ser un sujeto cosmopolita al estilo de Diógenes o de Epicuro, que uno estoico, como Séneca o Marco Aurelio, cuyo ideal influyó en Kant. El cosmopolitismo cínico de Diógenes o el hedonismo de Epicuro son el resultado de una polis envuelta en una crisis política profunda y expuesta a los vaivenes de la fortuna; ${ }^{22}$ mientras que el estoico, al menos en su versión romana, ya cuenta con cierta estabilidad y normalidad procuradas por el imperio.

Martha Nussbaum sostiene que la doctrina estoica puede ser una fuente para pensar la ciudadanía cosmopolita contemporánea. ${ }^{23}$ No obstante, los ideales cosmopolitas estoicos como autarquía, autosuficiencia o independencia, que resuenan en el ideal

\footnotetext{
${ }^{20}$ Nancy Fraser, Escalas de justicia (Barcelona: Herder, 2008), 21.

${ }^{21}$ Harvey, El cosmopolitismo, cap. 4. Como se dijo en la introducción, este texto no trata en sentido estricto de esferas de competencia formales ni de las escalas de gobernanza, sino de las formas de inserción de la agencia individual en órdenes diversos y complejos que deben ser tematizados y discutidos, cualesquiera que sean las formas que adopten. De ahí que se incluyan como meras ilustraciones de este tipo de problemas prácticos a autores como Held o Fraser, que han discutido distintos problemas de la democracia en las condiciones actuales que trascienden a los Estados nacionales, pero que aún no instituyen una instancia universal, global o cosmopolita de decisión que goce de cabal legitimidad. Estas referencias se pueden observar también en Harvey, quien, echando mano de la obra de Kant, denuncia el olvido de su interés por las condiciones reales de la autonomía y la razón práctica. No resulta entonces ocioso señalar la influencia de la filosofía estoica en Kant, rastreada por Nussbaum, y que se discute a continuación.

${ }^{22}$ Con la muerte de Alejando Magno, en el año 323 A.C., se desvaneció el ideal de un imperio universal. Dice Carlos García Gual: "La ciudad había perdido su autosuficiencia, su autárkeia tanto desde el punto de vista económico como político, y el destino de los ciudadanos no estaba ya en sus propias manos, sino en las del monarca correspondiente, y, acaso, por encima de él, en las de la Tyche, la Fortuna o el Azar, una divinidad imprevisible que ocupaba la vacante de los antiguos dioses patrones de la ciudad-estado", Carlos García Gual, Epicuro (Madrid: Alianza, 2018), 28-29.

${ }^{23}$ José Javier Benéitez Prudencio, "La ciudadanía cosmopolita de Martha Nussbaum", en Daimon. Revista Internacional de Filosofia (2010, sumplemento 3. Pensar el futuro): 347-354.
} 


\section{enn-claves}

kantiano de la autonomía, parecen realizarse mejor en cierto tipo de personas y grupos como son las élites académicas, empresariales, financieras o políticas (in)habitantes ${ }^{24} \mathrm{de}$ ciudades como Nueva York, Londres, Tokyo, Hong Kong o Ciudad de México. Es un despropósito cruel reclamar impasividad a personas pobres, excluidas, marginadas; migrantes económicos sin papeles, refugiados de conflictos armados o desplazados por el cambio climático, etcétera.

El cinismo y el hedonismo de Diógenes y de Epicuro, respectivamente, proponen comportamientos distintos: ponen de manifiesto el azar y la fortuna de la cuna y, con ella, de la contingencia de las formas de organización política en los diversos territorios. Estos dos filósofos, y sus discípulos - a diferencia de los estoicos, que pretenden ignorar o suprimir las condiciones materiales de la existencia humana- pondrán énfasis precisamente en estas mismas condiciones, hasta hacer de ellas un pivote fundamental de sus doctrinas y sus actitudes filosóficas. Por esta razón, tanto para sus ciudadanos contemporáneos de la polis, como para los ilustrados, tales doctrinas y las conductas que promovían resultaban desagradables y extravagantes.

Cuando Diógenes se proclama 'ciudadano del mundo' estaba significando algo negativo, quería decir que no pertenecía a ninguna polis. El suyo no es el cosmopolitismo del viajero interesado por culturas ajenas; se caracteriza mejor como reacción hacia cualquier tipo de coerción impuesta por la comunidad. No es casual que haya sido apodado El Perro. Los kynikoí llevaron una vida canina tomando el sol en el ágora o en el mercado, y haciendo sus necesidades a la vista de los demás. Lo que caracteriza a un perro es la falta de vergüenza, decencia y respeto. ${ }^{25}$ Sólo más tarde los estoicos darán un sentido más positivo al ideal cosmopolita. ${ }^{26}$

Judith Butler ha prestado mucha atención a la cuestión de la precariedad en las vidas de las personas, y a la aparición de los cuerpos en los espacios públicos. "[L]a palabra 'precariedad' describe exactamente la vida de aquellos cuyo 'lugar propio es el

\footnotetext{
${ }^{24}$ Uso la expresión "(in)habitantes" tratando de captar el sentido que tiene vivir en sitios intercambiables, que pueden ser como cualquier otro, con rasgos cuasi-idénticos, sin ningún tipo de arraigo.

${ }^{25}$ Carlos García Gual, La secta del perro. Diógenes Laercio. Vidas de los filósofos cínicos (Madrid: Alianza, 2019), 25.

${ }^{26}$ García Gual, Epicuro, 37-38.
} 


\section{enn-claves}

no-ser",. ${ }^{27}$ Es decir, la gente desechable. A partir de aquí, Butler desarrolla una aproximación performativa de la política.

$\mathrm{Su}$ enfoque trata de las implicaciones de los cuerpos en el lenguaje, una implicación que se confía pueda convertir a dichos cuerpos en interrogantes, en paradojas y problemas para la política normalizada; es la escenificación que dramatiza los esquemas convencionales de inteligibilidad que gobiernan la vida social; ${ }^{28}$ son las acciones de sentarse, de no moverse, de tomar un lugar, de apropiarse de él o de desplazarse. De manera general, en este tipo de acciones lo más inquietante es la materialidad de los cuerpos-fuera-de-su-lugar, de un lugar asignado socialmente. ${ }^{29}$ Por esta misma razón, las desviaciones sociales son estigmatizadas como desórdenes mentales o síntomas de enfermedad psiquiátrica por sus "incorrecciones situacionales voluntarias [que] constituyen pruebas de que el individuo no está dispuesto a mantenerse en su lugar". 30

Negros con letreros que reclaman que sus vidas importan ("Black lives matter"), que son personas ("I am a man") y que sueñan ("I have a dream"); mujeres diciendo que 'lo personal es político' o que 'su cuerpo su decisión', mientras lo exhiben desnudo o dramatizan un aborto, pero también las mujeres musulmanas con velo en público. La comunidad LGBTTTIQ con desfiles sexualmente expresivos "Estamos aquí, somos raros. Acostúmbrense"; deudores y desempleados con consignas "No son recortes, son ejecuciones", "No somos mercancías de políticos y banqueros"; migrantes económicos, desplazados o refugiados expresando que "Ningún ser humano es ilegal"; pueblos indígenas anunciando "Estamos vivos", etcétera.

Todas estas imágenes expuestas en espacios abiertos ilustran el sentido que Butler atribuye a la política performativa, y recuerdan los gestos de Diógenes, quien

\footnotetext{
${ }^{27}$ Judith Butler y Athena Athanasiou, Desposesión: lo performativo en la politica (Buenos Aires: Eterna Cadencia, 2017), 35-36.

${ }_{29}^{28}$ Butler y Athanasiou, Desposesión, 105.

${ }^{29}$ David Le Breton sostiene que desde los orígenes del pensamiento sociológico está presente una sociología implícita del cuerpo, especialmente en el estudio de la degeneración de las poblaciones más pobres, de la condición obrera. David Le Breton, La sociología del cuerpo (Buenos Aires: Nueva Visión, 2002), 12-13.

${ }^{30}$ Erving Goffman, Relaciones en público. Microestudios del orden público. Madrid: Alianza, 1979), 346347.
} 


\section{en-claves}

masturbándose en la vía pública respondía al ser reconvenido: “¡Ojalá fuera posible frotarse también el vientre para no tener hambre!’. Solía entrar al teatro topándose con todos cuando salían al término de una obra. Diógenes va siempre a contracorriente, tratando de sacudir a los demás, de hacerles ver lo ridículo y absurdo de muchas costumbres y prácticas comunes. Sólo con el discurso, sin la aparición, presencia y contacto de los cuerpos fuera de (su) lugar, sería difícil comprender el sentido profundo de lo que quiere decir. Al aparecer en lugares antes insospechados y con gestos impúdicos la gente dice cosas haciéndolas: estorbar, distraer, interrumpir, molestar, es parte de lo que se tiene para expresar. De modo que dice mucho más el gesto valiente de Rosa Parks, sentada en un espacio segregado resistiendo humillaciones e insultos, que la decisión de la Corte Suprema que declara "iguales... pero separados".

Sin embargo, no sólo los grupos desaventajados dicen cosas haciéndolas impúdicamente: la manada en España, los porkys y las muertas de Juárez, en México recuerdan acremente a las mujeres cuál es su lugar en la ciudad. No pueden estar solas ni mucho menos divertirse de la misma manera que los hombres porque saben a lo que se arriesgan y se exponen. Por tanto, son responsabilizadas por el daño sufrido. También es el caso de los migrantes hispanos en Estados Unidos, objeto de cacerías humanas llevadas a cabo por ciudadanos milicianos como los Minutemen o los Patriotas Constitucionales - ellos se lo buscan como invasores de un lugar que no es suyo-.

Se debe decir que este texto no propone una versión narrativa de la participación política, como lo ha descrito Hannah Arendt y lo han recuperado Seyla Benhabib ${ }^{31}$ o Julia Kristeva. ${ }^{32}$ Las personas y colectivos disidentes muchas veces no tienen tampoco acceso privilegiado a sus propias historias. Sus narrativas pueden presentar sesgos e información interesada. El objetivo es más elemental. Sin descartar un ejercicio de cruce hermenéutico entre diversas concepciones de democracia, justicia o bienestar, esto deberá acontecer con posterioridad. Nuestra propuesta es más limitada y busca responder en forma específica a los gestos que acompañan cada una de las denuncias, prestando especial atención a la

\footnotetext{
${ }^{31}$ Seyla Benhabib, The Reluctant Modernism of Hannah Arendt (Thousand Oaks, CA: Sage Publications, 1996), 129; Seyla Benhabib, Situating the Self. Gender, Community and Postmodernism in Contemporary Ethics (Nueva York: Routledge, 1992), 276.

${ }^{32}$ Julia Kristeva, Hannah Arendt. Life Is a Narrative (Toronto: University of Toronto Press, 2001), 320.
} 


\section{enn-claves}

dimensión espacial que ocupan materialmente los cuerpos. Las posiciones relativas de las personas y los grupos connotan inclusión/exclusión, dentro/fuera, central/marginal. Lo original consistiría en pasar por el tamiz de las preguntas de la democracia el trazado de las fronteras y la ocupación de esas posiciones: quién, cómo, por qué y bajo qué procedimientos y reglas determina que alguien esté adentro, arriba y al centro de cualquier lugar.

\section{La agencia en condiciones complejas: la democracia, la ciudad y la política en un entorno globalizado}

Saskia Sassen observa que sobre el territorio concebido como parte de lo estatal-nacional en todo el mundo suceden una serie de procesos de diferente envergadura local, nacional y global. ${ }^{33}$ La cuestión planteada por Sassen trata temas similares a los expuestos por Nancy Fraser ${ }^{34}$ o Edward Soja. ${ }^{35}$ Habitamos localidades donde se asientan procesos multiescala, desde el hogar — pasando por las fábricas, los mercados, las urbanizaciones y las regiones - hasta el Estado nacional y el orden internacional.

El problema es que estos procesos no se corresponden necesariamente con las formas de organización de los lugares ni con las disposiciones de los agentes que Kant imaginó estarían habilitados para ejercitar su autonomía reflexiva en cada una de estas esferas: personal, cívica y cosmopolita. Puede ocurrir que ciudades cosmopolitas en lo informacional, tecnológico y económico, operen graves problemas de daño y exclusión en la gestión del territorio que concierne a los servicios públicos y la calidad de vida de las personas; o que impongan a los Estados instituciones y reglas que estén más allá de su poder de supervisión, sujeción y control. En este tipo de situaciones la capacidad de las personas de ir y venir de arriba a abajo entre todos esos planos conduciría a la frustración y al desencanto, porque no estaría acompañada en la realidad de los medios idóneos para

\footnotetext{
33 Saskia Sassen, Territorio, autoridad y derechos. De los ensamblajes medievales a los ensamblajes globales (Buenos Aires: Katz Editores, 2010), 22.

${ }^{34}$ Fraser, Escalas de justicia, 370.

${ }^{35}$ Soja, Seeking Spatial Justice.
} 


\section{enn-claves}

ejercer sus libertades con relativa efectividad para desarrollar sus vidas con decoro y dignidad.

Este texto no trata la cuestión de las escalas de gobernación o gobernanza. En el presente, con los Estados nacionales coexisten estructuras transnacionales y globales. Hay un debate no concluyente aún sobre la forma en la que se podrían organizar las relaciones entre los distintos órdenes de gobierno, además de las relaciones que se tendrían que establecer con formas de integración social no políticas, verbigracia los mercados. Por un lado, se podría mencionar a optimistas como Luigi Ferrajoli, ${ }^{36}$ quien habla de domesticar los poderes salvajes con un constitucionalismo social, de derecho privado o global; o confían en la posibilidad de establecer instancias de gobernación cosmopolitas acordadas por estados nacionales como David Held; ${ }^{37}$ y, por el otro, a autores más escépticos como Dani Rodrik, ${ }^{38}$ quien sostiene que simultáneamente no se puede tener democracia, soberanía y mercados.

Lo que es innegable es que no existe un orden global con un agente intencional identificado capaz de coordinar, organizar, supervisar y controlar la economía y la política; los mercados de bienes o de capitales; las relaciones interestatales de los gobiernos, pese a que se pueda reconocer la importancia de instancias de derecho internacional público y privado; tratados, acuerdos comerciales, tribunales y arbitrajes, etcétera. La fuerza relativa de las posiciones de negociación de las partes en todos esos asuntos parece determinar el curso de las relaciones internacionales. No se puede decir que sean instancias de justicia cosmopolitas.

El objetivo es mucho más modesto, y, sin embargo, no es poco ambicioso. Consiste en dar cuenta de que todas estas formas de organización política y sus relaciones con los mercados y otros subsistemas sociales (como la ciencia y la técnica, por ejemplo), cualesquiera que sean sus mecanismos de integración y reglas, aterrizan de modos

\footnotetext{
${ }^{36}$ Luigi Ferrajoli, Constitucionalismo más allá del Estado (Madrid: Trotta, 2018), 96, y Poderes salvajes: la crisis de la democracia constitucional (Madrid: Trotta, 2009), 112.

${ }^{37}$ David Held, La democracia y el orden global. De Estado moderno al gobierno cosmopolita (Barcelona: Paidós, 1997), 174.

${ }^{38}$ Dani Rodrik, Hablemos claro sobre el comercio mundial. Ideas para una globalización inteligente (Barcelona: Ediciones Deusto, 2018), capítulo 1, edición Kindle.
} 


\section{en-claves}

singulares sobre espacios físicos concretos y afectan de modo ineludible a las personas que los habitan.

Lo ambicioso está del lado de la propuesta de que, en dirección inversa a esta lógica que se da por sentada, los aterrizajes territoriales locales de estos procesos multiescala también se deban - y puedan - enjuiciar e influir en una dirección diferente o eventualmente contraria a las formas usuales en que acontecen como si fueran inevitables, necesarios o naturales, pero con enfoques comunicativos, y en el plano de intercambios personales o cara a cara ${ }^{39}$ Esto no significa que exista en todos los casos la suficiente capacidad para descifrar, definir, controlar o contener dichos procesos, pero siempre se retiene alguna para ejercer sobre ellos y sus dinámicas algunas resistencias, para entorpecerlos o allanarles el camino. En la medida que en su implantación concurren causas complejas y multifactoriales, no se puede decir que esas resistencias sean idóneas para lograr los objetivos perseguidos intencionadamente por parte de los agentes, pero no son inocuas ni inútiles. Los cuerpos ocupando los espacios físicos, sus dichos junto con sus dramatizaciones son medios potentes que obligan a prestar atención y a reflexionar sobre los defectos de la política. Con independencia del desenlace de la protesta social, el caso de las empresas que buscan instaurar industrias extractivas en territorios indígenas muestra el deber de dialogar, reconociendo las especificidades de la cultura, la región y el territorio físico, comprendido ahora como lugares experienciales, con significados simbólicos para las personas y pueblos.

Con esto se quiere redignificar el lugar de la política-política, de la participación de la gente cara a cara, hombro con hombro, a ras del suelo. Por eso importan las manifestaciones y las movilizaciones en las calles y en los parques tras el fracaso de los parlamentos, los tribunales y la administración como los lugares habituales de la política. La dimensión performativa de la política, las aglomeraciones, las asambleas y los

\footnotetext{
${ }^{39}$ Esta idea está presente en Anthony Giddens y Ulrich Beck, quienes sostienen que en la modernidad reflexiva se atribuye a las personas un tipo de saberes prácticos que les permiten ajustar sus vidas a las prácticas más o menos complejas en las que sus vidas se desarrollan. Anthony Giddens, Modernidad e identidad del yo. El yo y la sociedad en la época contemporánea (Barcelona: Península, 2000), 304; Ulrich Beck, Modernidad reflexiva. Política, tradición y estética en el orden social moderno (Madrid: Alianza, 1997), 272.
} 


\section{enn-claves}

movimientos: desplazar, migrar, invadir, avanzar, abrir; pero también estar, permanecer, cerrar, resguardar, avanzar, retroceder en ciertos espacios. En casi todas estas expresiones la dimensión del espacio y de los territorios es crucial, y suelen percibirse como subversión o transgresión ${ }^{40}$ en las maneras, discursos e imágenes que son dignas de ser vistas, oídas, e incluso olidas, ${ }^{41}$ en el lugar que se ocupa. Por lo tanto, no son acciones puramente simbólicas; dicen e implican cosas que pueden ser interpretadas, pese a que las batallas sucedan las tantas veces dramatizadas y expresadas mediante metáforas. Habría situaciones corrientes de comunicación en las que se entiende bien de lo que se habla, bajo un marco común de comprensión, y situaciones excepcionales que expresan desacuerdos profundos.

Un problema tal vez sea que los ideales de democracia y justicia que constituyen el asiento de nuestras ideas de libertad, autonomía y agencia individual, así como las concepciones y doctrinas principales sobre los derechos humanos, de cuño primordialmente liberal, sean por su contexto de surgimiento refractarias a determinados temas y formas de expresión de las demandas y protestas. En sus orígenes, las personas titulares de derechos humanos fueron los varones adultos burgueses independientes y autosuficientes. Por esta razón, la organización estatal de lo público no daba cuenta de la vulnerabilidad humana: alimento, vestido, techo, salud, educación, empleo, seguridad social, niñez, vejez, sexualidad, eran temas ajenos a los intereses públicos dignos de ser vistos y debatidos. La administración de la necesidad fue concebida en términos subsidiarios por el Estado liberal, como asunto de las familias y las comunidades. Todo lo

\footnotetext{
${ }^{40}$ Como observa José Ignacio Lanzagorta García sobre las marchas del orgullo LGBTI, éstas han dejado de ser transgresoras: "Hoy, el Estado, al menos en algunos países o entidades dentro de estos, no sólo acompaña la marcha, sino que la procura, la publicita, la protege. Hoy, algunas empresas buscan patrocinarla y hacerse notoriamente presentes. Aunque hay todo un lado oscuro para el que no, hay otro luminoso en el que hacer esto da prestigio y, sobre todo, abre un mercado lucrativo; José Ignacio Lanzagorta García, "Transgresión sexual en el espacio público: notas sobre la 41 marcha del orgullo", en La Brújula. El Blog de la Metrópoli (blog), Nexos, 2 de julio de 2019, https://labrujula.nexos.com.mx/?p=2408.

${ }^{41}$ Existen olores desagradables asociados a grupos de personas constituidos racialmente, por factor de clase socioeconómica, e incluso por razón de sexo; véase Anthony Sinnott, "Sociología del olor", en Revista Mexicana de Sociología 65, núm. 2 (abril-junio, 2003): 431-464.
} 


\section{enn-claves}

relacionado con la reproducción de la vida humana - a diferencia de la producción y el intercambio- es privado y prepolítico. ${ }^{42}$

La comprensión liberal de la vida pública deja en la sombra todo el trabajo reproductivo que se realiza en el entorno doméstico y lo relacionado con la llamada economía del cuidado. ${ }^{43}$ Estas doctrinas económicas no equivalen, como se defiende, a una racionalidad puramente técnica e instrumental. Suponen una racionalidad que es política y que debería ser evaluada en términos de su justicia. ${ }^{44}$ Es decir, ofrecen una matriz de inteligibilidad que reemplaza lo político por la gobernanza tecnocrática. ${ }^{45}$ Esta racionalidad se implanta en las instancias del régimen democrático y en el Estado nacional con sus formas de representar los intereses; en la gestión de la ciudad y lo urbano con una ordenación particular de los espacios públicos, comunes y privados; así como en la concepción de la política y la policía, que dispone ciertas reglas de participación decorosa, decente y cívica.

Al concebirse a la población en estos términos, bajo una categoría neutral de la ciudadanía sin atributos de sexo, raza, etnia, edad, condición, etcétera, se organizó la dimensión del territorio también ignorando especificidades físicas y geográficas. Los Estados nacionales, tienden a asumir que la geografía y la población son uniformes y homogéneas.

En el ámbito local las divisiones territoriales son ciegas a las formas tan diversas en las que se piensa a sí misma la gente que habita en cada territorio, sea, por ejemplo, como pueblos, comunidades o regiones. La representación política de signo liberal es

\footnotetext{
${ }^{42}$ Se ha criticado a Hannah Arendt por proyectar esta imagen de la política con sus distinciones entre acción, trabajo y labor, expuesta en La condición humana (Barcelona: Paidós, 1998), 361; Amartya Sen y Martha Nussbaum han criticado al liberalismo por invisibilizar la necesidad y la vulnerabilidad humana. Véase Amartya Sen, Desarrollo y libertad (México: Planeta, 2000), 504; Martha C. Nussbaum, Las fronteras de la justicia (Barcelona: Paidós, 2007), 448.

${ }^{43}$ Véase Katrine Marcal, ¿Quién le hacía la cena a Adam Smith? Una historia de las mujeres y la economía (México: Debate, 2017), 264.

${ }^{44}$ Dice Soja que la justicia o injusticia serían infundidas en las geografías multiescala en las que vivimos, desde la intimidad del hogar hasta el desarrollo inequitativo de la economía global. Soja, Seeking Spatial Justice, 19.

${ }^{45}$ Butler y Athanasiou, Desposesión, 59-60.
} 


\section{enn-claves}

representación de los intereses particulares de individuos, no de las colectividades. ${ }^{46} \mathrm{El}$ problema, según Immanuel Wallerstein, es que esta ceguera es apreciada como una virtud del liberalismo, ${ }^{47}$ que trata de neutralizar las condiciones geográficas, económicas, culturales, históricas y los reclamos de dichos pueblos con una comprensión limitada de la imparcialidad y con ignorancia grave de las circunstancias materiales que habilitan las capacidades humanas para el ejercicio de su autonomía y autodeterminación política.

Este texto se pregunta por el tipo de instituciones, procedimientos o movimientos sociales capaces de habilitar de modo transversal la agencia personal en las dimensiones significadas por Immanuel Kant del modo que sea más amplio e incluyente, y por las formas de organizar los espacios, territorios y entornos físicos para que sean capaces de desarrollar dignamente nuestra vida como animales humanos vulnerables y dependientes del medio ambiente. Dice Soja: "Todos los que son oprimidos, subyugados, o económicamente explotados están hasta cierto grado sufriendo los efectos de geografías injustas, y estas luchas pueden ser usadas para construir una mayor unidad y solidaridad transversal". ${ }^{48}$ La idea de Soja es que añadir la dimensión espacial a la reflexión y al debate públicos puede ser una estrategia efectiva como adhesivo organizacional y motivacional, un pegamento que pueda conducir y mantener coaliciones heterogéneas y plurales. $^{49}$

Llama la atención que el tipo de prácticas que desafían la concepción tradicional de esfera pública, los parlamentos, plazas y calles donde se reconocen ciertas conductas como cívicas y decentes, cobra forma mediante la exhibición dramática y la ocupación de los cuerpos de esos espacios, y también de otros lugares insospechados para personas y grupos excluidos y marginados, cuya aparición y presencia arruina el paisaje, ensuciándolo. Esto significa que la resistencia, la protesta y la acción opositora disidentes y desobedientes - , hacen visibles en la política el significado de "estar-fuera-

\footnotetext{
${ }^{46}$ Este tema ha sido ampliamente tratado en México por Luis Villoro. Entre otros de sus textos se puede ver Estado plural. Pluralidad de culturas, (México: Paidós, 1998) o De la libertad a la comunidad (México: Fondo de Cultura Económica, 2004).

${ }^{47}$ Immanuel Wallerstein, Geopolitica y geocultura. Ensayos sobre el moderno sistema mundial (Barcelona: Kairós, 2007) 336.

${ }^{48}$ Soja, Seeking Spatial Justice, 24.

${ }^{49}$ Ibid., 24.
} 


\section{en-claves}

de-lugar". ${ }^{50}$ Ahora bien, esta cuestión tiene que ser bien entendida, ya que reclamar un espacio o un lugar "no es meramente ganar acceso a lo que de por sí existe, sino que tiene que ver con transformar un lugar". ${ }^{51}$

\section{A manera de conclusión: el giro espacial de la filosofía política, limitaciones y retos}

Puede parecer romántico, utópico y hasta irresponsable en un contexto como el actual de crisis de legitimidad de las democracias representativas liberales y pluralistas proponer que la gente saliendo, ocupando o recuperando calles, plazas, fábricas, predios urbanos baldíos o residenciales, sea una manera razonable de perfeccionar los regímenes democráticos. El ascenso de movimientos sociales que reclaman una mayor participación e intervención en la toma de decisiones públicas, instancias de democracia directa, han dado pábulo a formas de pensar y hacer la política de características más demagógicas que lo habitual en cualquier campaña política, y en el extremo con aires populistas, dadas sus imágenes simplificadoras de la realidad y los problemas públicos, visiones maniqueas y polarizadoras de la sociedad entre élites corruptas y pueblo bueno.

Desde las democracias delegativas analizadas por Guillermo O'Donnell, ${ }^{52}$ pasando por los autoritarismos competitivos de Steven Levitsky y Lucan A. Way, ${ }^{53}$ hasta llegar a regímenes más autocráticos de tipo populista ${ }^{54}$ que atacan las instancias de representación, mediación y control del poder público, la apelación vertical a la voluntad popular, de arriba hacia abajo, suele ser utilizada por los gobernantes para legitimar acciones unilaterales, discrecionales y arbitrarias. ${ }^{55}$ Por lo tanto, las manifestaciones

\footnotetext{
${ }^{50}$ Ibid., 36-41.

${ }^{51}$ Ibid., 41.

52 Guillermo O’Donnell, “Delegative Democracy”, en Journal of Democracy 5, núm. 1 (enero, 1994): 5569.

53 Steven Levitsky y Lucan A. Way, "Elections Whitout Democracy: The Rise of Competitive Autoritarianism", en Journal of Democracy 13, núm. 2 (abril, 2002): 51-65.

${ }^{54}$ La bibliografía sobre populismos es cada vez más amplia, lo que da muestra de los sentimientos en nuestra época hacia las democracias representativas pluralistas y liberales. Véanse Fernando Vallespín y Máriam M. Bascuñán, Populismos (Madrid: Alianza, 2017), 304, y Ernesto Laclau, La razón populista (Buenos Aires: Fondo de Cultura Económica, 2005), 312.

${ }^{55}$ Varios riesgos de las democracias directas y sus mecanismos institucionales son descritos por Alicia Lissidini, Yanina Welp y Daniel Zovatto (coords.), Democracia directa en Latinoamérica (Buenos Aires:
} 


\section{en-claves}

masivas, plantones y marchas cargan con la sospecha de ser impulsadas por líderes carismáticos y autoritarios.

¿Se puede hablar entonces de una democracia liberal si sus instituciones tradicionales están deslegitimadas debido a su alejamiento de la gente y a su ineficacia? La percepción popular es que las instituciones representativas han sido capturadas por élites, y no dan acceso con iguales oportunidades para participar, hablar, intervenir e influir en las decisiones colectivas.

Otro problema, empero, es que incluso la mejor voluntad, preparación y dedicación de los gobernantes, no mejoraría de inmediato los resultados en bienestar y derechos a toda la ciudadanía. Existen siempre problemas en la implementación de las políticas públicas que no tienen mucho que ver con el régimen político. Muchos temas son instrumentales, de las burocracias y los sistemas económicos, científicos, tecnológicos, ambientales, etcétera, que limitan la capacidad de los gobiernos. Este tema lo trató O’Donnell en la distinción entre régimen y Estado que hemos referido contrastándola con otras distinciones relativas al giro espacial de la política: la ciudad como idea no es lo mismo que la urbanización, ni la política como ideal es lo mismo que la policía como realidad mundana con uniformes y cachiporras. La realidad material, el espacio físico, el entorno local y los códigos de intercambio de los diferentes (sub)sistemas sociales aterrizados en cada lugar de la experiencia humana, como parlamentos, tribunales, plazas, calles, mercados, fábricas, campo, hogares, etcétera, deben conducirnos a evaluar caso a caso cómo se ejercitan las libertades humanas contextualmente.

Piénsese en las crisis de los parlamentos y gobiernos de varios Estados-nación europeos en donde un sinnúmero de competencias ha sido expropiadas en el nivel supranacional, con consecuencias dramáticas en Grecia, o también en el caso de América Latina, por ejemplo. $\mathrm{O}$ en la reflexión sobre sentencias favorables en materia de derechos

Prometeo Libros, 2008), 301; y Alicia Lissidini, Yanina Welp y Daniel Zovatto (comps.), Democracias en movimiento. Mecanismos de democracia directa y participativa en América Latina (México: Universidad Nacional Autónoma de México, 2014), 348. 


\section{en-claves}

sociales, económicos, sociales y ambientales pero que no tienen eficacia sobre el mundo. ${ }^{56}$

Lo que no es posible es enumerar un catálogo cerrado a priori de buenas y eficaces prácticas allende las formas tradicionales de la democracia representativa que han sido convenidas y reflexionadas desde un constitucionalismo liberal o republicano. La perspectiva contextual, local, visibiliza las formas en las que suceden y acomodan las relaciones humanas en el seno de cada subsistema social, institución, práctica o tradición, y echa luz sobre sus principios y reglas: lo del equilibrio reflexivo que se mencionaba antes de la mano de John Rawls. Creo que esto es lo que busca enseñar Thomas Pogge ${ }^{57}$ al reflexionar sobre el funcionamiento de los sistemas de patentes en medicamentos, por ejemplo, que no difiere mucho del enfoque de Jon Elster ${ }^{58}$ cuando revisa diversos esquemas de justicia de asignación de bienes públicos distintos a la justicia global del Estado nación para los que se piensa la justicia pública. Los dos autores muestran lugares concretos de donde uno es excluido: quiénes, cómo y por qué.

La injusticia sentida sobre los cuerpos, en los lugares y espacios de la experiencia personal, contradice y desnuda las promesas inalcanzables de sistemas sociales económicos, políticos o culturales, pretendidamente universales. Si el poder político se piensa solamente desde el punto de vista de la Constitución, de la soberanía, en términos jurídicos, se descuida cómo de hecho se ejerce "concretamente y en detalle, con toda su especificidad, sus técnicas y sus tácticas". ${ }^{59}$ Por lo tanto, deben considerarse también en la base las formas de enfrentar esos engranajes y "eslabones más finos de la red de poder". ${ }^{60}$ Cuando se subordina el tema del poder, que es el tema principal de la democracia y la política, a la instancia económica y la lógica del interés, los otros problemas humanos terminan siendo de poca importancia.

\footnotetext{
${ }^{56}$ Malcolm Langford, César Rodríguez Garavito y Julieta Rossi (eds.), La lucha por los derechos sociales. Los fallos judiciales y la disputa por su cumplimiento (Bogotá: Editorial Dejusticia, 2017), 614.

57 Thomas Pogge, "Innovaciones farmacéutica: ¿debemos excluir a los pobres?, en Hacer justicia a la humanidad (México, Fondo de Cultura Económica / Universidad Nacional Autónoma de México / Comisión Nacional de Derechos Humanos, 2009), 393-457.

58 Jon Elster, Justicia local: de qué modo las instituciones distribuyen bienes escasos y cargas necesarias (Barcelona: Gedisa, 1994), 312.

${ }^{59}$ Michel Foucault, Microfísica del poder (Madrid: Las Ediciones de la Piqueta, 1979), 180.

${ }^{60}$ Ibidem.
} 


\section{enn-claves}

Puede tenerse imaginación institucional para fortalecer los regímenes pluralistas y liberales con división de poderes; contrapesos de diversos tipos; órganos autónomos; contralorías ciudadanas; mecanismos de democracia directa y participativa, etcétera. Pero nada garantiza la inclusión plena ni acceso efectivo a los derechos. No existen instituciones democráticas a prueba de sospecha. ${ }^{61}$ Aunque sus principios y valores constitutivos sean sólidos, sus reglas pueden ocasionar resultados subóptimos y negativos dada la complejidad de un entorno que no es susceptible de control.

¿De qué trata entonces este texto y cuál es su propuesta programática? Como se dijo antes, la idea es simple, pero a la vez ambiciosa: la parte simple busca recuperar una intuición de la gente cuando expresa la necesidad de democratizar la sociedad, la escuela, los mercados, la fábrica o el hogar. Esta idea está de algún modo presente en Norberto Bobbio, ${ }^{62}$ del lado de la democracia procedimental, o Boaventura de Sousa Santos, ${ }^{63}$ de lado de la concepción sustantiva. En ambos casos, sin embargo, no se sabe bien cuál sería el significado práctico de sus propuestas, cómo se traducirían institucionalmente.

La parte difícil, complicada consiste en la reflexión sobre los mecanismos sociales de resistencia o de allanamiento a las instituciones económicas, políticas y culturales. Cómo se puede idear desde la base, al ras del suelo, cara a cara, estrategias de inserción o rechazo, de conformidad o de crítica a esas instituciones, pero que tengan aptitud de orientarlas en la dirección de esos ajustes recíprocos entre una democracia liberal igualitaria y un Estado legal-burocrático; entre una ciudad incluyente y una urbanización autárquica y dinámica; entre una política también liberal igualitaria y una policía guardiana del orden. El equilibrio reflexivo de John Rawls o la dialéctica de Edward Soja entre las intuiciones personales sobre lo bueno y lo justo, por un lado, y sobre la necesidad de (sobre)vivir juntos - que impone una serie de condicionamientos técnicos, materiales y sistémicos - es una exigencia en sociedades plurales y complejas como las actuales. O, como dice Rainer Forst, "Nadie está enteramente absorbido dentro de la

61 Éste es el tema principal de Pierre Rosanvallon, Contrademocracia. La política en la era de la desconfianza (Buenos Aires: Manantial, 2007), 312.

${ }^{62}$ Norberto Bobbio, El futuro de la democracia (México: Fondo de Cultura Económica, 1986), 42.

${ }^{63}$ Boaventura de Sousa Santos, Democracia y transformación social (México: Siglo XXI, 2017), 159. 


\section{en-claves}

práctica de justificación en la que participa, porque siempre es posible sujetar esa práctica al cuestionamiento y el criticismo". ${ }^{64}$

Las preocupaciones personales de la gente pobre en los espacios de su vida cotidiana, en sus hogares y empleos, han propiciado reacciones, por ejemplo, el Brexit, en el Reino Unido, o el ascenso de Donald Trump en los Estados Unidos con un discurso proteccionista. Estas reacciones confirman lo insinuado por Dani Rodrik: no puede tenerse simultáneamente las tres cosas soberanía, democracia y mercados. Dos países perfectamente insertados en la economía global demuestran la fuerte tensión interna entre algunos de sus ciudadanos y sus élites políticas, económicas y culturales.

Sin embargo, criticar a los votantes del Brexit o Trump llevaría a una pobre conclusión, presa del prejuicio ilustrado que condena a los perdedores de la globalización económica. ${ }^{65}$ A ellos se les imputa la culpa de socavar a los regímenes democráticos en su justicia y la dinámica natural de los mercados en su bondad. Este relato ha sido criticado por autores como Pierre Bourdieu o Loïc Wacquant ${ }^{66}$ en su defensa de la idea de reflexividad. La pregunta de fondo debe ser acerca de si los sistemas político y económico en su constitución y funcionamiento normal ofrecen un lugar real para todas las personas con independencia de su condición y su identidad. Como vio Michel Foucault, esto no se puede verificar en el mero discurso sino en las relaciones personales y los lugares cotidianos: parlamentos, burocracia, calles, plazas, fábricas, universidades, parques y sitios de recreo, etcétera.

Por eso, la reflexividad no es un imperativo sólo de las personas como individuos aislados en la dimensión vital-local. Debe también ir en el sentido inverso de parte de los

\footnotetext{
${ }^{64}$ Rainer Forst, Justification and Critique: Towards a Critical Theory of Politics (Cambridge: Polity Press), 2014.

65 "El Brexit o la elección de Trump no son accidentes de la historia política británica o de Estados Unidos, sino las claras consecuencias de una precarización (muy precoz en los países en que los entramados sociales son escasos y débiles) de la base de las clases medias británica y estadounidense", Guilluy, No Society, edición Kindle, loc. 265.

${ }^{66}$ La reflexividad "se impone más que nunca como un imperativo absoluto a todos los que se quieren resistir eficazmente a esos conceptos de pacotilla — 'globalización' y 'flexibilidad', 'multiculturalismo' y 'comunidad', 'identidad', 'hibridación', 'fragmentación', etcétera- cuya difusión, en el campo universitario y fuera de él, acompaña en el mundo entero la puesta en marcha de la política neoliberal de destrucción del Estado social y de sus experiencias históricas, entre ellas la autonomía de la ciencia social; es decir, su existencia misma”, Pierre Bourdieu y Loïq Wacquant, Una invitación a la sociología reflexiva (Buenos Aires: Siglo XXI, 2005), 8.
} 


\section{enn-claves}

impulsores de tales regímenes políticos y sistemas económicos para que se revise sus ficciones acerca de la gente, de los valores y principios que presumiblemente ordenan sus vidas, y se hagan cargo seriamente de las condiciones materiales, vulnerabilidad y precariedad de la vida humana que acaecen en determinados lugares y bajo experiencias situadas. Por lo tanto, se deben comprender bien los lugares y su demografía, sus cualidades y condiciones de sostenibilidad, así como sus significados culturales, antes de implantarse cualquier política.

La complejidad no hace eludible la tarea. Al final, de facto, todas las personas tratamos de ajustarnos, acomodarnos o, por el contrario, resistir, arreglar y transformar los espacios que habitamos, transitamos o visitamos. Cómo percibimos lo que nos toca en estos espacios no se corresponde necesariamente con los datos objetivos del mundo, ni tampoco auxilia para identificar qué sea lo que funciona bien y qué sea lo que falla. No obstante, en la medida en que los efectos de la política y de la economía son reales sobre nosotros, como reales son también las reacciones que las soportan o que las desafían, la búsqueda de esos equilibrios es una tarea permanente y tendría que ser concebida como un proceso de aprendizaje, pero uno que no está exento de retrocesos. ${ }^{67}$ Como señala Bourdieu y Wacquant, no es la misma la actitud del sociólogo que estudia el sistema educativo y sus políticas, que la de un padre de familia que busca encontrar una buena escuela para su hija. ${ }^{68}$

Cuando mamá y papá constatan que la escuela cerca de su barrio para su hija no satisface ciertas expectativas, que por ejemplo su título y las habilidades que recibió no tienen salida laboral, o que están por debajo del nivel de aptitud requerida, pueden percatarse mejor de la injusticia de la segregación espacial y de la distribución de las mejores y peores escuelas bajo patrones de clase social, estatus o regiones. Donde el régimen democrático, la ciudad y la política ofrecían una igual condición, derechos y

\footnotetext{
67 "La educación no es nunca una actividad puramente intencional, los modos de relación, la dinámica afectiva de la estructura familiar, la manera en que el niño se sitúa en esa trama de la sumisión o la resistencia que oponga, dan lugar a coordenadas que son consideradas cada vez más importantes en la socialización (...) Si bien el orden social se infiltra a través del espesor vivo de las acciones del hombre para tomar allí fuerza de ley, este proceso no se termina nunca por completo", en David Le Breton, La sociología del cuerpo (Buenos Aires: Nueva Visión, 2002), 9. (Él énfasis es propio).

${ }^{68}$ Bourdieu y Wacquant, Una invitación, 115.
} 


\section{en-claves}

oportunidades equivalentes, los padres y madres se topan todos los días con una administración y una burocracia educativa estatal, con una urbanización y una policía que son refractarias al acceso de las niñas y niños pobres, con discapacidad, indígenas, transgénero, etcétera. Este rechazo y exclusión son ostensibles en la arquitectura del espacio con muros, vallas, e incluso con indumentaria distinta que marca las distancias y señala quiénes pertenecen a qué lugares y quiénes no.

De esta manera, se nota la injusticia de un sistema escolar que se organiza con una dinámica que llega al extremo de cerrar las puertas en el rostro de una niña indígena pobre, por ese solo hecho. De esta constatación en el terreno surge como un impulso potente el imperativo de transformar los espacios escolares en zonas de libre acceso a todas las niñas y niños, con total independencia de su condición y la de sus padres, sea lo que sea que tenga que hacerse. La injusticia del sistema educativo se revela en este caso en los muros que dividen el adentro y el afuera, no tanto en el problema de la escasez, sino en dónde se traza la frontera, quién la traza y con qué legitimidad. A fin de cuentas, es un problema de la democracia en el sentido indicado por Bobbio: como "conjunto de reglas (primarias y fundamentales) que establecen quién está autorizado para tomar las decisiones colectivas y bajo qué procedimientos". ${ }^{9}$

\footnotetext{
${ }^{69}$ Norberto Bobbio, El futuro de la democracia (México: Fondo de Cultura Económica, 1996), 24.
} 


\section{enn-claves}

\section{Bibliografía}

Arendt, Hannah. La condición humana. Barcelona: Paidós, 1998.

Beck, Ulrich. Modernidad reflexiva. Política, tradición y estética en el orden social moderno. Madrid: Alianza, 1997

Benéitez Prudencio, José Javier. "La ciudadanía cosmopolita de Martha Nussbaum". Daimon. Revista Internacional de Filosofia (2010, sumplemento 3. Pensar el futuro): 347-354. https://revistas.um.es/daimon/article/view/119511.

Benhabib, Seyla. Situating the Self. Gender, Community and Postmodernism in Contemporany Ethics. New York: Routledge, 1992.

Benhabib, Seyla. The Reluctant Modernism of Hannah Arendt. Thousand Oaks, CA: Sage Publications, 1996.

Bobbio, Norberto. El futuro de la democracia. México: Fondo de Cultura Econóica, 1986.

Borja, Jordi, y Manuel Castells. Local y global. La gestión de las ciudades en la era de la información. Madrid: Taurus, 1997.

Bourdieu, Pierre, y Loiq Wacquant. Una invitación a la sociología reflexiva. Buenos Aires: Siglo XXI, 2005.

Butler, Judith, y Athena Athanasiou. Desposesión: lo performativo en la política. Buenos Aires: Eterna Cadencia, 2017.

Elster, Jon. Justicia local: De qué modo las instituciones distribuyen bienes escasos y cargas necesarias. Barcelona: Gedisa, 1994.

Fainstein, Susan S. "Planificación, Justicia y Ciudad". Urban, núm. 6 (septiembrediciembre, 2014): 7-20.

Fainstein, Susan S. The Just City. Ithaca, NY: Cornell University Press, 2011. Edición Kindle.

Ferrajoli, Luigi. Constitucionalismo más allá del Estado. Madrid: Trotta, 2018.

Ferrajoli, Luigi. Poderes salvajes: la crisis de la democracia constitucional. Madrid: Trotta, 2009. 
Forst, Rainer. Justification and Critique: Towards a Critical Theory of Politics.

Cambridge: Polity Press, 2014.

Foucault, Michel. Microfísica del poder. Madrid: Las Ediciones de la Piqueta, 1979.

Fraser, Nancy. Escalas de justicia. Barcelona: Herder, 2008.

García Gual, Carlos. Epicuro. Madrid: Alianza, 2018.

García Gual, Carlos. La secta del perro. Diógenes Laercio. Vidas de los filosófos cínicos. Madrid: Alianza, 2019.

Giddens, Anthony. Modernidad e identidad del yo. El yo y la sociedad en la época contemporánea. Madrid: Alianza, 1997.

Goffman, Erving. Relaciones en público. Microestudios del orden público. Madrid: Alianza, 1979.

Guilluy, Christophe. "El problema de la izquierda es que está encerrada en su sociología y las grandes ciudades". De Daniel Gascón. Letras Libres, 8 de Julio de 2019.

Guilluy, Christophe. No Society. El fin de la clase media occidental. Barcelona: Penguin Random House, 2019.

Harvey, David. El cosmopolitismo y las geografias de la libertad. Madrid: Akal, 2017.

Held, David. La democracia y el orden global. Del Estado moderno al gobierno cosmopolita. Barcelona: Paidós, 1997.

Kant, Immanuel. Teoría y práctica. Madrid: Tecnos, 1993.

Kristeva, Julia. Hannah Arendt. Life is Narrative. Toronto: University of Toronto Press, 2001.

Laclau, Ernesto. La razón populista. Buenos Aires: Fondo de Cultura Económica, 2005.

Langford, Malcolm, César Rodríguez Garavito, y Julieta Rossi (eds.). La lucha por los derechos sociales. Los fallos judiciales y la disputa por su cumplimiento. Bogotá: Editorial DEjusticia, 2017.

Lanzagorta García, José Ignacio. "Transgresión sexual en el espacio público: Notas sobre la 41 marcha del orgullo". La Brújula. El Blog de la Metrópoli (blog). Nexos, 2 de Julio de 2019. https://labrujula.nexos.com.mx/?p=2408. 
Levitsky, Steven, y Lucan A. Way. "Elections Without Democracy: the Rise of Competitive Autoritarianism". Journal of Democracy 13, núm. 2 (2002): 51-65.

Lissidini, Alicia, Yanina Welp y Daniel Zovatto (coords.). Democracia directa en Latinoamérica. Buenos Aires: Prometeo Libros, 2008.

Lissidini, Alicia, Yanina Welp y Daniel Zovatto (comps.). Democracias en movimiento. Mecanismos de democracia directa y participativa en América Latina. México: Universidad Nacional Autónoma de México, 2014.

Nussbaum, Martha C. Las fronteras de la justicia. Barcelona: Paidós, 2007.

O'Donnell, Guillermo. "Delegative Democracy". Journal of Democracy 5, núm. 1 (1994): 55-69. https://doi.org/10.1353/jod.1994.0010.

O'Donnell, Guillermo. Democracia, Agencia y Estado. Teoría con intención comparativa. Buenos Aires: Prometeo, 2010.

Pereyra, Carlos. Sobre la democracia. México: IEPCEJ, 2012.

Pogge, Thomas. "Innovaciones farmacéutica: ¿debemos excluir a los pobres?". En Hacer justicia a la humanidad, 393-457. México: Fondo de Cultura Económica / Universidad Nacional Autónoma de México / Comisión Nacional de Derechos Humanos, 2009.

Rancière, Jacques. El desacuerdo. Política y filosofía. Buenos Aires: Nueva Visión, 1996. Rawls, John. El derecho de gentes y "Una revisión de la idea de razón pública". Barcelona: Paidós, 2001.

Rawls, John. La justicia como equidad: una reformulación. Barcelona: Paidós, 2002. Rodrik, Dani. Hablemos claro sobre el comercio mundial. Ideas para una globalización inteligente. Barcelona: Deusto, 2018.

Rosanvallon, Pierre. Contrademocracia. La política en la era de la desconfianza. Buenos Aires: Manantial, 2007.

Sassen, Saskia. Territorio, autoridad y derechos. De los ensamblajes medievales a los ensamblajes globales. Buenos Aires: Katz Editores, 2010.

Sen, Amartya. Desarrollo y libertad. México: Planeta, 2000. 


\section{enn-claves}

Sinnott, Anthony. "Sociología del olor". Revista Mexicana de Sociología 65, núm. 2 (2003): 431-464.

Soja, Edward. Seeking Spatial Justice. Minneapolis: University of Minnesota Press, 2010.

Sousa Santos, Boaventura de. Democracia y transformación social. México: Siglo XXI, 2017.

Vallespín, Fernando, y Máriam M. Bascuñán. Populismos. Madrid: Alianza, 2017.

Wallerstein, Immanuel. Geopolítica y cultura. Ensayos sobre el moderno sistema mundial. Barcelona: Kairós, 2007. 